\title{
Osteogenesis Imperfecta Type IV
}

National Cancer Institute

\section{Source}

National Cancer Institute. Osteogenesis Imperfecta Type IV. NCI Thesaurus. Code C98576.

A type of osteogenesis imperfecta that is characterized by fractures and hearing loss. It is more severe than type I and less severe than types II and III. 